\title{
Kosten des Factorings
}

Kosten entstehen dem Factoringkunden durch die Factoringgebühr als Entgelt für die Risikoübernahme und die Dienstleistungen sowie durch Zinsen für die Bevorschussung der Forderungen. Die Factoringgebühr lässt sich aufspalten in einen Dienstleistungs- und einen Delkredereanteil. Der Delkredereanteil ist das Entgelt für das übernommene Risiko des Forderungsausfalls. Dienstleistungs- und Delkredereanteil zusammen bewegen sich zwischen $0,5 \%$ und $2,5 \%$ der angekauften Rechnungsbeträge.

Für die Finanzierung der Forderungen stellt der Factor zusätzlich zur Factoringgebühr Zinsen für den Zeitraum vom Ankauf der Forderung bis zum Eingang der Zahlung des Debitors in Rechnung. Zahlt der Debitor nicht, so berechnet der Factor Zinsen bis zum vereinbarten Zeitpunkt, zu dem die Forderung als ausgefallen gilt, üblicherweise 90 bis 120 Tage nach Fälligkeit der Forderung. Die Höhe der Zinsen entspricht banküblichen Sätzen für Kontokorrentkredite. In der Regel wird der Zins auf den gesamten Forderungsbetrag berechnet, obwohl nur 80 bis $90 \%$ der Forderung finanziert werden. Das vom Factor bis zum Zahlungseingang zurückgehaltene Bardepot verzinst sich dann mit einem niedrigeren Guthabenzins. 